\title{
Strength of Brazed Joint and Joint Thickness for Cemented Carbide / Silver Brazing Filler Metal
}

\author{
Kyogo Watabe ${ }^{\mathrm{a}}$, Kazuya Mori ${ }^{\mathrm{a}, *}$, Meribe Richard Chukwuma ${ }^{\mathrm{a}}$, \\ Yuki Fujishita ${ }^{\text {b }}$ Koji Kirihara ${ }^{b}$, Kazufumi Sakata ${ }^{\mathrm{b}}$ \\ ${ }^{a}$ Kumamoto University, 2-39-1 Kurokami, Chuo-ku, Kumamoto, 860-8555, Japan \\ ${ }^{b}$ Nakayama Seimitsu Co., Ltd., 3606 Komori, Nishihara, Aso, 861-2402, Japan \\ *Corresponding Author: kmori@mech.kumamoto-u.ac.jp
}

\begin{abstract}
One of the most common methods for joining materials in manufacturing is the process of brazing. Brazing is widely used in many areas such as space engineering, marine engineering and electrical engineering, just to name a few. Brazing is a commonly used engineering solution due to its versatility and low cost. Brazing is used in making Poly-Crystalline Diamond (PCD) tools. While these tools are highly durable and have a long operating life the brazing can negatively affect these qualities with variations in strength especially with tools that are small.

In this paper the causes of these variations in joint strength of a small area have been investigated using the four point bending and the cantilever beam bending tests. The parent material used was cemented carbide and the brazing filler metal was silver based. Three types of brazing were used; flame brazing, induction brazing and furnace brazing. The results revealed that the brazing joint thickness affected the strength. The optimal thickness for maximum strength has been identified.
\end{abstract}

Keywords: brazing, polycrystalline diamond tool, bending strength, joint thickness.

\section{Introduction}

Brazing is one of the most common methods for joining materials in manufacturing. It is widely used in many areas such as space engineering, marine engineering and electrical engineering. It is often the engineering solution of choice in manufacturing with many advantages. One of its appeals is the uniformity of the process in which the connection of materials is completed simultaneously creating a consistently strong bond without the problems of temperature difference which welding has. It is therefore a good method in bonding materials of varying thicknesses as well as being able to bond a wide variety of materials at a reasonable cost.

Figure 1 shows an application of brazing on a polycrystalline diamond (PCD) tool. A blank is made by sintering PCD on cemented carbide in high pressure and at high temperature. A cutting blank is cut out from the blank and then brazed onto a parent material. The PCD tool has high wear and heat resistance.

Figure 2 shows an example of a PCD punch. In manufacturing there is a demand for increasingly smaller and smaller punches however with smaller tools the inconsistency of brazing strength has become a problem ${ }^{(1)}$. This inconsistency in the brazing strength can result defective manufacturing tools.

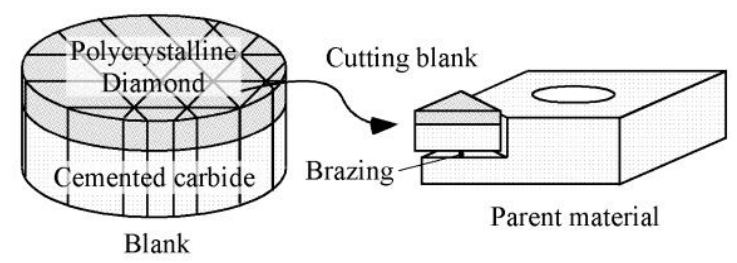

Fig. 1. Polycrystalline Diamond Tool.

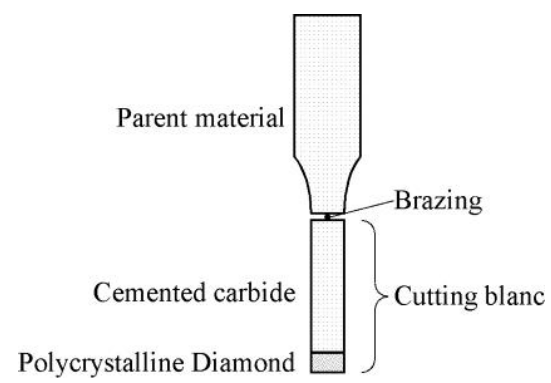

Fig. 2. Polycrystalline Diamond Punch. 
In this paper the factors affecting the inconsistency of brazing strength of a small area have been investigated, firstly using the four point bending test in which we used flame brazing, induction brazing and furnace brazing to determine the best method. And secondly the cantilever beam bending test was used to determine the optimal joint thickness.

\section{Four Point Bending Test}

Strength data was obtained experimentally using the four point bending test on three brazing methods; flame brazing, induction brazing and furnace brazing. The furnace brazing was conducted in a vacuum.

\subsection{Specimen}

Figure 3 shows one of the four point bending specimens. The cross section of the specimen is square and its side length is $4 \mathrm{~mm}$. The parent material was cemented carbide $(\mathrm{G} 4)$ and the brazing filler metal was Incusil ABA of Morgan Advanced Ceramics, Inc. The chemical components of the brazing filler metal were 59.0\% $\mathrm{Ag}$, $27.25 \% \mathrm{Cu}, 12.50 \% \mathrm{In}$ and $1.25 \% \mathrm{Ti}$. The mechanical properties of the parent material and the brazing filler metal are shown in Table 1. The surfaces of the brazing were grinded down by a grinding disk with \# 600 to \#800 grain size prior to brazing.

The brazing specifications of three brazing methods are shown in Table 2. The heating time required for the flame and induction brazing was determined based on the workers' observations and the heating was finished when the brazing filler metal melted completely. Flux was used in the flame and induction brazing to prevent oxidization of the surfaces.

\subsection{Experimental Method}

The best method for investigating the strengths of the brazing joints is the tensile test. However, it is very difficult to make tensile test specimens. So the four point bending test was used. The distance between the lower fulcrums was $30 \mathrm{~mm}$ and $10 \mathrm{~mm}$ for the upper fulcrums as shown in Fig. 3. The loading speed was five millimeters per minute.

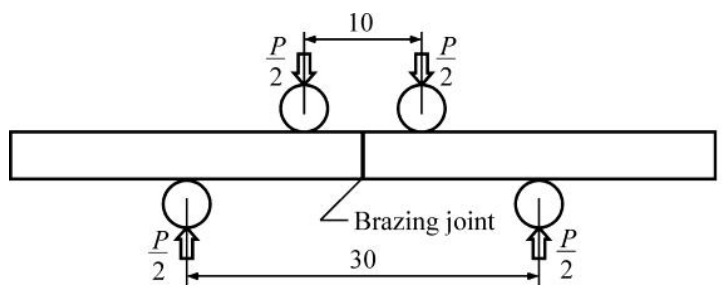

Fig. 3. Four point bending specimen.

\subsection{Experimental Results}

The bending strengths of the specimens made by the three methods are shown in Table 3 and Fig. 4. Table 3 shows the averages and the standard deviations. Figure 4 shows the strength plotted on a normal probability paper. There were 10 specimens for each method.

The results show that while there are inconstancies in the strengths there are no such inconsistences between the three methods. In other words, the type of method used isn't significant.

Table 1. The mechanical properties of the parent material and the brazing filler metal.

\begin{tabular}{|c|c|c|}
\hline & Brazing Filler metal & Parent material \\
\hline Young's modulus [GPa] & 76 & 570 \\
\hline Poisson's ratio [-] & 0.36 & 0.23 \\
\hline Tensile strength [MPa] & 445 & 1270 \\
\hline $0.2 \%$ proof stress [MPa] & - & 2940 \\
\hline Yield strength [MPa] & 338 & - \\
\hline
\end{tabular}

Table 2. Brazing specifications.

\begin{tabular}{|c|c|c|c|}
\hline & Heating & Cooling & Flux \\
\hline Flame brazing & $\begin{array}{c}\text { Melting point } \\
\text { (propane gas) }\end{array}$ & Natural cooling & F100 \\
\hline Induction brazing & Melting point & Natural cooling & F200H \\
\hline Furnace brazing & $\begin{array}{c}\text { Heating } \rightarrow \text { Holding } \\
\left(750^{\circ} \mathrm{C}, 15 \mathrm{~min} .\right)\end{array}$ & $\begin{array}{c}\text { Furnace cool } \\
(3 \sim 3.5 \mathrm{~h})\end{array}$ & Nothing \\
\hline
\end{tabular}

Table 3. Average strength and standard deviation.

\begin{tabular}{|c|c|c|}
\hline & $\begin{array}{c}\text { Average strength } \\
{[\mathrm{MPa}]}\end{array}$ & $\begin{array}{c}\text { Standard deviation } \\
{[\mathrm{MPa}]}\end{array}$ \\
\hline Flame brazing & 662 & 293 \\
\hline Induction brazing & 968 & 375 \\
\hline Furnace brazing & 835 & 271 \\
\hline
\end{tabular}

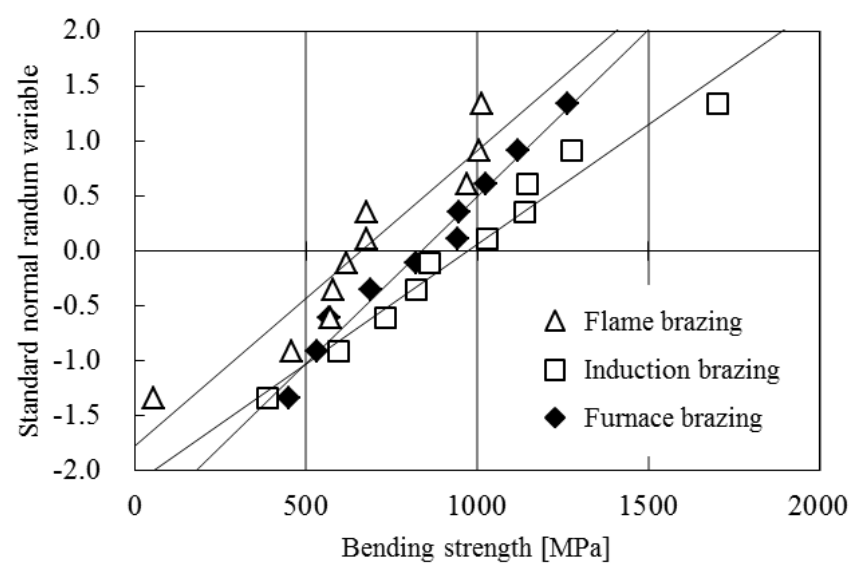

Fig. 4. Bending strengths plotted on a normal probability paper. 


\subsection{Observing Fracture Surfaces}

To investigate the reason why the strengths vary widely the fracture surfaces were observed as shown in Figs. 5 to 7. The upper portion of the pictures corresponds to the upper fulcrums and the lower portion corresponds to the lower fulcrums which means that the upper area has been compressed while the lower area has effected by tension. The right and the left pictures show the joint specimens butterflied open.

Figure 5 shows the fracture surfaces with the maximum strength (a) and the lowest strength (b) from the flame brazing specimens. The fracture surface from the maximum strength (Fig. 5 (a)) shows thick layer and a fine pattern while the surface from the lowest strength specimen has brazing residue that has peeled off.

Figure 6 shows the fracture surfaces from the maximum and lowest strength using induction brazing. The residue of brazing material appears thicker than that of the lowest strength specimen.

Figure 7 shows the fracture surfaces from the maximum and lowest strength using furnace brazing. There appears to be no clear difference between these specimens.

From these results it can be concluded that there is a probability that the strength of the brazing joints becomes weaker with less the joint thickness. It has been commonly assumed that the smaller the gap and therefore the smaller

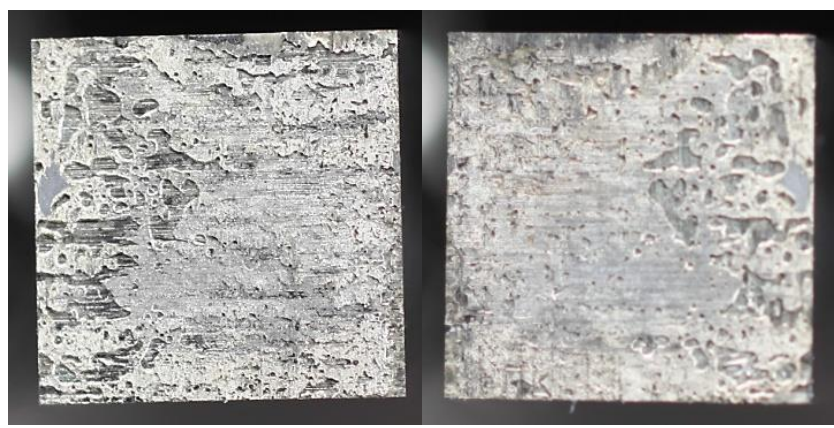

(a) The maximum strength (1014 MPa)

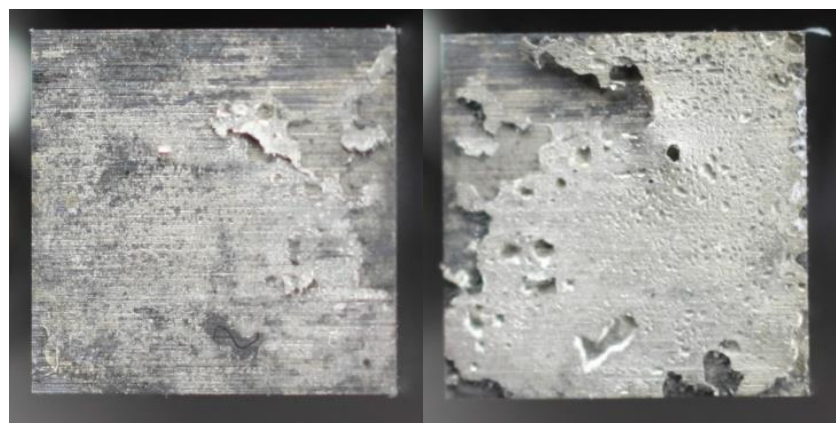

(b) The lowest strength (52 MPa)

Fig. 5. Fracture surface of flame brazing. the joint thickness used the higher the strength ${ }^{(2),(3)}$.

Therefore the relationship between the thickness of the brazing layer and its strength was further investigated by using cantilever bending tests. The reason for using cantilever testing was because the thickness of the brazing layer would easily be controlled.

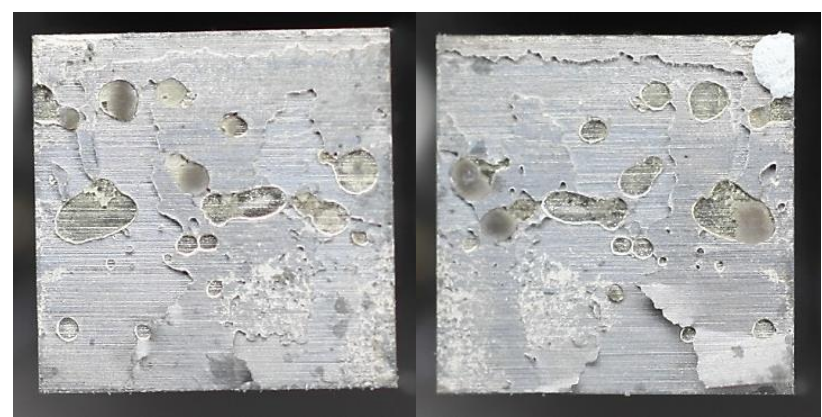

(a) The maximum strength (1701 MPa)

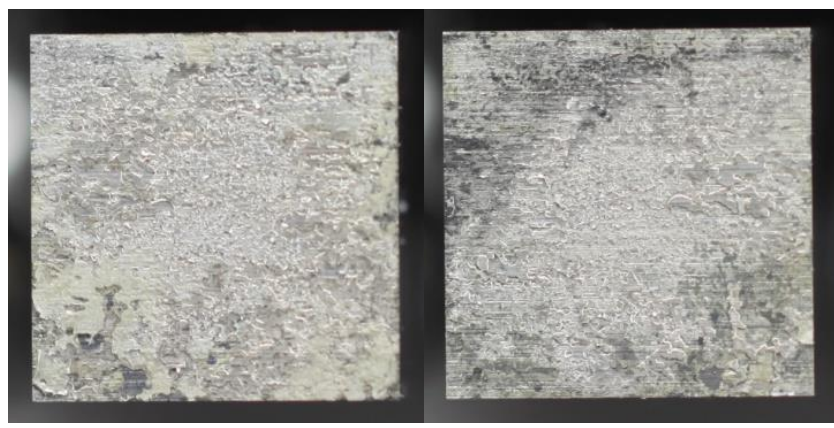

(b) The lowest strength (385 MPa)

Fig. 6. Fracture surface of induction brazing.

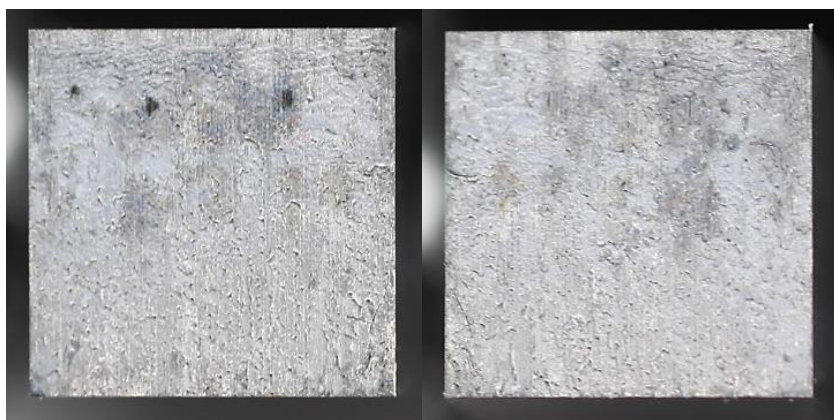

(a) The haighest strength (1364 MPa)

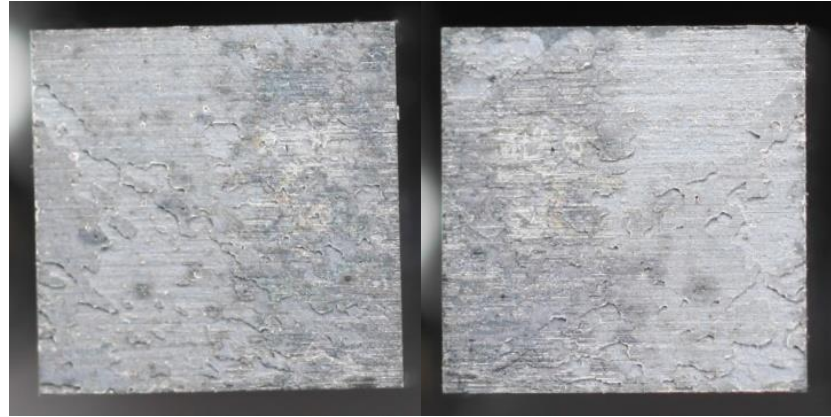

(b) The lowest strength (449 MPa)

Fig. 7. Fracture surface of furnace brazing. 


\section{Cantilever Beam Bending Test}

By testing cantilever beam specimens, the relationship between the brazing layer thickness and the brazing joint strength was examined. Furnace brazing was the only brazing method used because the brazing thickness using this method could be controlled.

\subsection{Specimen}

Figure 8 shows a cantilever beam specimen. The parent material and the brazing material were the same as the four point mending specimens as well as the dimensions of the cross section of the beam.

During the testing, the cantilever specimens were placed vertically in a furnace as shown in Fig. 9. The thickness of the brazing layer was controlled by the amount of weight put on the beam. When weight was placed on the beam the pressure between the joint surfaces was $50 \mathrm{kPa}$ while it was $3.6 \mathrm{kPa}$ without any weight.
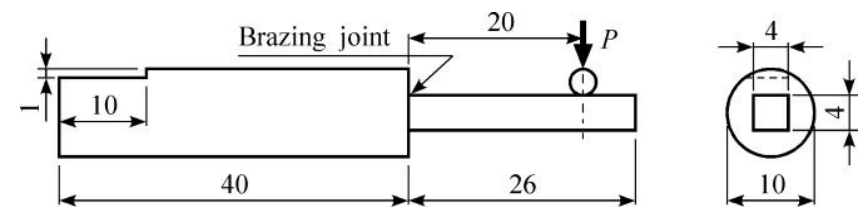

Fig. 8. Cantilever beam specimen.

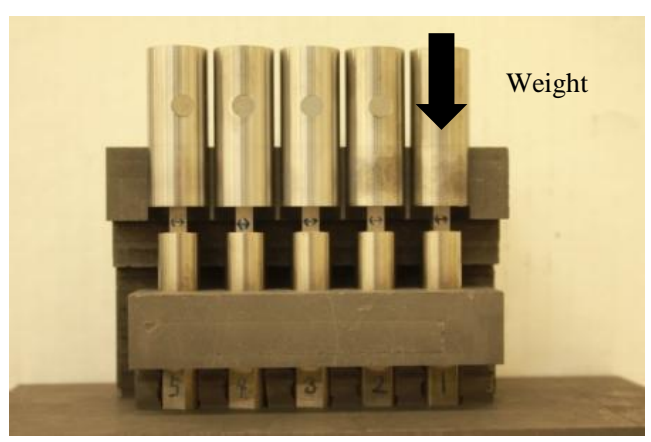

Fig. 9. Weights put on specimens.

\subsection{Experimental Method}

The bending test of the cantilever beam specimen was carried out. The distance between the loading point and the brazing joint was $20 \mathrm{~mm}$ as shown in Fig. 8. The loading speed was $5 \mathrm{~mm}$ per minute.

\subsection{Experimental Results}

The thickness of the brazing was measured by a 3D microscope. A sample image is shown in Fig. 10. The color indicates the height of the fracture surface. The colors represent the thickness of the brazing layer.

The bending strengths of the cantilever beam bending specimens made by furnace brazing are shown in Fig. 11. The closed circles are $3.6 \mathrm{kPa}$ while the open circles are 50 $\mathrm{kPa}$.

Figure 11 shows that the strength becomes weaker with less the joint thickness. Furthermore, the strength may weaker when the thickness is too thick. Which, it seems that there is an optimal thickness for the strength and that is around $25 \mu \mathrm{m}$. Generally, it is said that the strength of brazing joint increases as the thickness becomes thinner ${ }^{(2) \text {, }}$ (3).

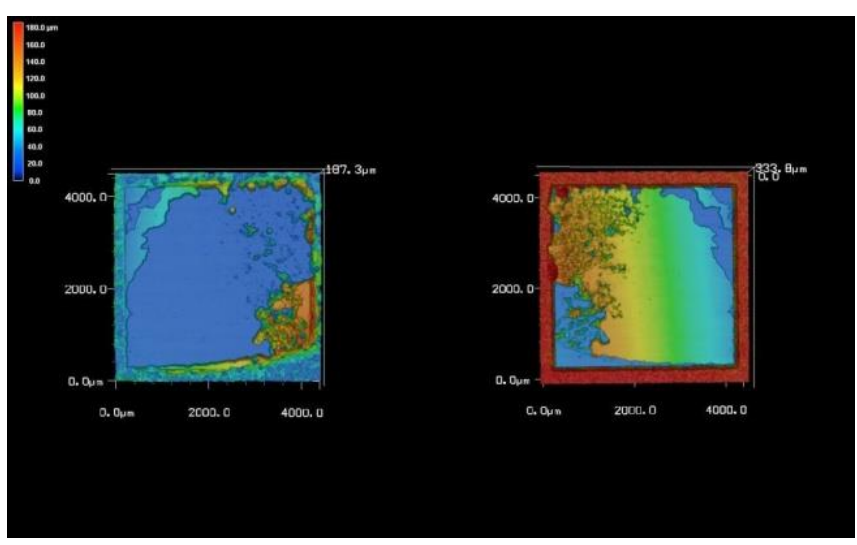

Fig. 10. 3D microscope image.

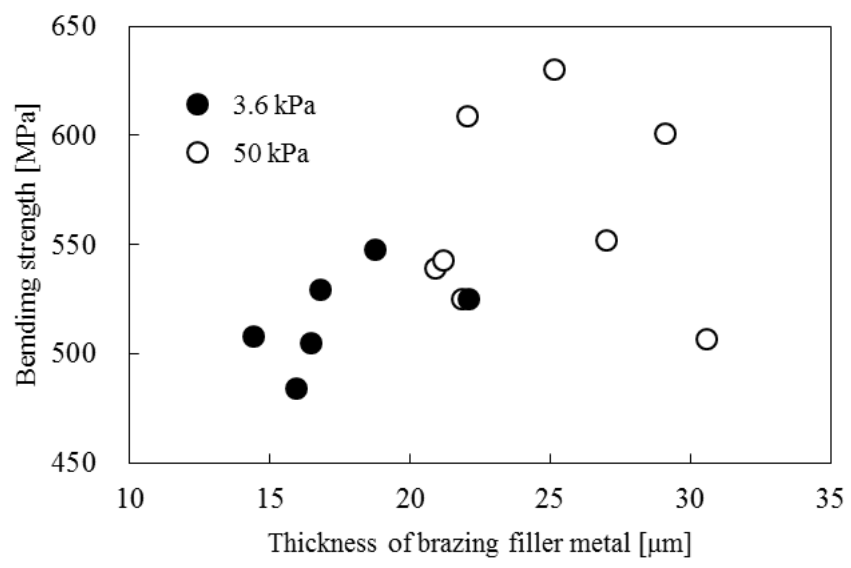

Fig. 11. Brazing joint thickness and bending strength.

\section{Discussion}

The optimal thickness of brazing layer was evaluated by the Finite Element Analysis. The analysis was conducted in two dimensions and the mesh pattern is shown in Fig. 12. The stress distribution of the upper part of the cross section can be assumed to be uniform because the joint thickness is quite thin in companion with the specimen. Reliable results can be obtained by the two dimensional analysis with the 
same reasoning. The material properties of the Finite Element Analysis were the same values as the experiments as shown in Table 1.

Figure 13 shows the strain of the finite element of the maximum stress in the elements of the brazing filler metal. Figure 13 shows that the strain of the element becomes lowest when the joint thickness is around $20 \mu \mathrm{m}$. So the strength of the brazing joint becomes the maximum when the joint thickness is around $20 \mu \mathrm{m}$. This result coincides approximately with the experimental result. The value of 20 $\mu \mathrm{m}$ varies depending on the material properties of the brazing filler metal and the parent material.

In conclusion the maximum strength of brazing joint of cemented carbide and silver brazing filler metal can be obtained by keeping the thickness of the brazing joint of around 20 to $25 \mu \mathrm{m}$. The large difference in the elastic properties of the brazing filler metal and the parent material produces the maximum thickness of brazing layer to achieve maximum strength.

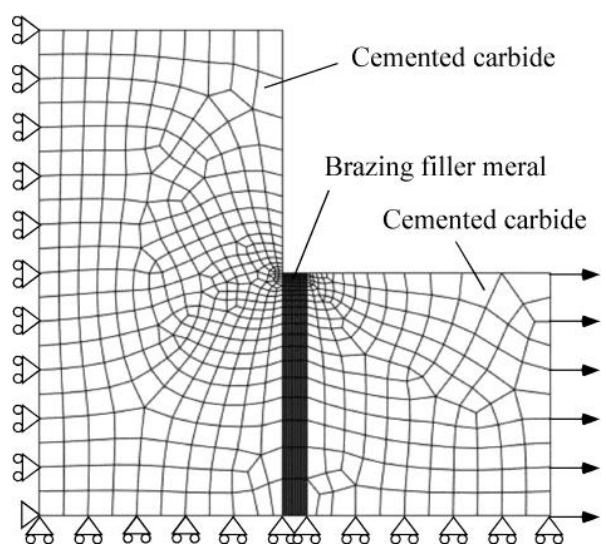

Fig. 12. Mesh pattern of the Finite Element Analysis.

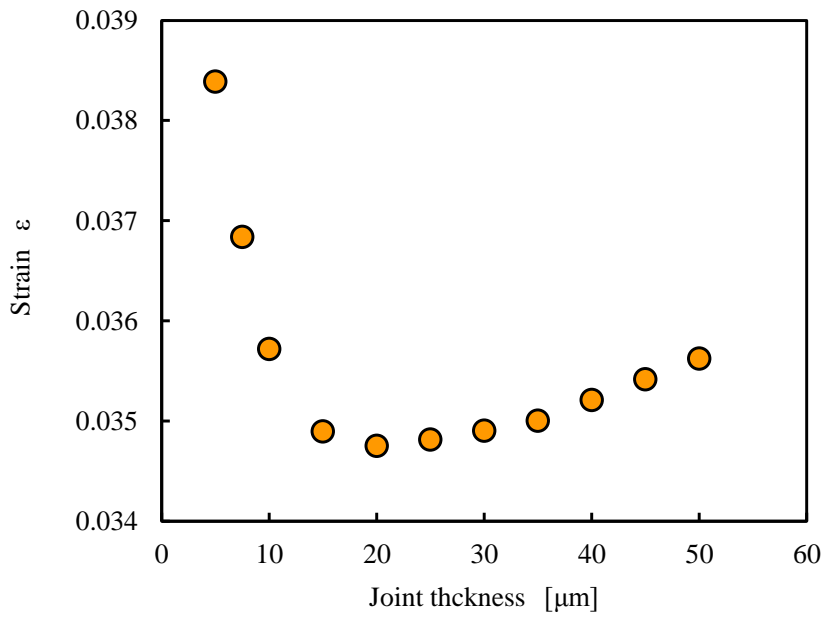

Fig. 13. Strain at the maximum stress element.

\section{Conclusions}

In this paper the factors that affect the brazing joint strength of a small area for cemented carbide and silver brazing filler metal was examined. According to the results our conclusions are as follows;

(1) There is no significant difference in terms of strength between the brazing methods; flame brazing, induction brazing and furnace brazing. The inconsistencies in strengths were the same regardless of the method used.

(2) The optimal thickness of brazing layer is around 20 to $25 \mu \mathrm{m}$ to achieve maximum strength.

\section{References}

(1) Kyogo Watabe, Takuya Iguchi, Kazuya Mori, Yuki Fujishita, Takeshi Eguchi, Kazufumi Sakata : "Effect of Brazing Thickness to Brazing Strength of Cemented Carbide Cantilever Beam," Japan Society of Mechanical Engineers, M\&M 2012 Strength of Material Conference, OS1209, CD-ROM, 2012.

(2) M. H. Sloboda : "Design and Strength of Brazed Joints," Revision of an article first appearing in Welding and Metal Fabrication, JOHNSON MATTHEY METALS LIMITED, pp. 1-11, 1961.

(3) Y. Ishii, T. Onzawa : "Fundamental Aspects of Brazing and Soldering," Journal of the Japan Welding Society, Vol. 37, No. 7, pp. 58-667, 1968. 